\title{
A Simple Densitometric Method for the Quantification of Inhibitory Neurotransmitter Gamma-Aminobutyric Acid (GABA) in Rat Brain Tissue
}

\author{
Chidambaram Saravana Babu, ${ }^{1}$ Krishnamoorthy Selvarajan Kesavanarayanan, ${ }^{1}$ \\ Periyathambi Kalaivani, ${ }^{1}$ Vijayan Ranju, ${ }^{1}$ and Muthiah Ramanathan ${ }^{2}$
}

${ }^{1}$ Centre for Toxicology and Developmental Research, Sri Ramachandra University, Chennai, TN-600 116, India
${ }^{2}$ PSG College of Pharmacy, Post Box No 1674, Peelamedu, Coimbatore, TN 641 004, India

Correspondence should be addressed to Muthiah Ramanathan, muthiahscommun@gmail.com

Received 4 July 2010; Accepted 16 December 2010

Academic Editor: Teresa Kowalska

Copyright (C) 2011 Chidambaram Saravana Babu et al. This is an open access article distributed under the Creative Commons Attribution License, which permits unrestricted use, distribution, and reproduction in any medium, provided the original work is properly cited.

\begin{abstract}
Gamma-aminobutyric acid (GABA) is the major inhibitory neurotransmitter in the mammalian central nervous system which is involved in various physiological and pathological processes. The present study demonstrates a simple high-performance thinlayer chromatography (HPTLC) method which was developed for the estimation of GABA in rat brain tissue. The method was validated in terms of precision, recovery, reproducibility, and variability. Instrumental precision was found to be $0.5891 \% \mathrm{CV}$ and reproducibility of the method was found to be $0.4141 \% \mathrm{CV}$. Interday and intraday precision of the method was found to be $0.9453 \%$ and $1.3236 \%$ CV, respectively. Accuracy of the method was checked by the recovery study, and the average recovery of GABA was found to be $97.98 \%$ at $40 \mathrm{ng}$ and $96.15 \%$ at $80 \mathrm{ng}$ levels. The present HPTLC method for GABA estimation was found to be simple, precise, reproducible, sensitive, and accurate. No doubt, this proposed method will be a useful tool for the estimation of GABA in rat brain tissue.
\end{abstract}

\section{Introduction}

Central nervous system (CNS) operates by a fine-tuned balance between excitatory and inhibitory signalling. Gammaaminobutyric acid (GABA) is the major inhibitory neurotransmitter and it was serendipitously discovered in the mammalian brain in 1949 [1-3]. Dysfunction of the GABAergic system was showed to be associated with schizophrenia, cerebral stroke, temporal lobe epilepsy (TLE), Parkinson's disease (PD), Huntington's disease (HD) and anxiety disorders, and so forth [4-8]. GABAergic system is also implicated in cognitive processes, such as memory formation and consolidation $[9,10]$. Interestingly, GABAergic system is one of the rapidly emerging therapeutic targets for various neurological disorders [11-13]. Understanding the importance and role of GABA in various neurological disorders and determination of GABA in biological samples will be of great use to study the pathological status and also to investigate the significance of the therapeutic interventions.

Various analytical techniques such as fluorimetry [13], high-performance liquid chromatography (HPLC) [14], gas chromatography (GC) [15], and capillary electrophoresis [16] are employed to estimate GABA in biological samples. Since most of the amino acids are aliphatic in nature, they require derivatization in order to be detected by UV/Visible detectors. In liquid chromatography methods like HPLC and GC, complex procedures like precolumn derivatization with various ion pairing reagents and electrochemical detection are applied for the separation and quantification of GABA [17]. Further, the experimental procedure and complexity in the sample preparation for the above-mentioned techniques are tedious. In view of the biological importance, there has been a spurt of interest in the development of new analytical methods to estimate GABA in brain tissue. The present 


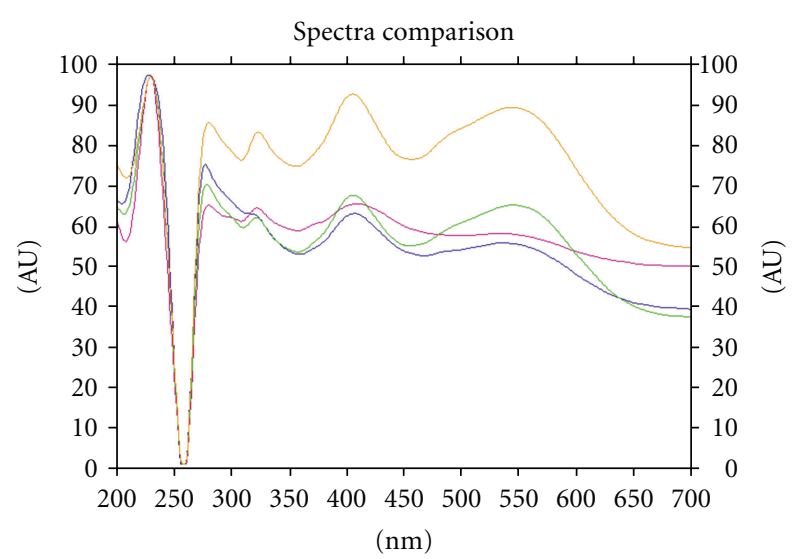

Figure 1: Overlay UV absorption spectra of GABA in standard and rat brain tissue.

study demonstrates a simple, feasible, cost-effective HPTLC method for estimation of GABA in rat brain tissue.

\section{Methods}

2.1. Chemicals and Materials. GABA (ultra pure) was purchased from Sigma, USA. Precoated HPTLC silica plates were obtained from Merck, Mumbai. All the chemicals and solvents used were of analytical grade, procured from Qualigens Fine Chemicals, India.

2.2. Animal Ethics Statement. The study protocol was approved by the Institutional Animal Ethics Committee (IAEC) of Sri Ramachandra University, Chennai, India.

2.3. Animals. Male Sprague-Dawley rats, (270-330g) obtained from Central Animal Facility, Sri Ramachandra University, Chennai, India were used for the study. Animals were housed in individual polycarbonate cages in a well ventilated room (air cycle: 15/min; $70: 30$ ) under an ambient temperature of $23 \pm 2{ }^{\circ} \mathrm{C}$ and $40 \%-65 \%$ relative humidity, with artificial photoperiod 12-h light/dark cycle. Experimental animals were provided with standard rodent pellet diet (Nutrilab Rodent, Tetragon Chemie, India) and purified water ad libitum (RIOS, USA). Animals were acclimatized for 7 days to the laboratory conditions prior to the initiation of the study. Guide for the Care and Use of Laboratory Animals (Institute of Laboratory Animal Resources, National Academic Press 1996; NIH publication number \#85-23, revised 1996) was strictly followed throughout the study.

2.4. Preparation of GABA Standard Solution. $0.1 \mathrm{~N} \mathrm{HCl}$ prepared in $80 \%$ ethanol (mentioned hereafter as $0.1 \mathrm{~N} \mathrm{HCl}$ ) was used to dissolve GABA standard. GABA stock solution $\left(1 \mathrm{mg} \mathrm{mL}^{-1}\right)$ was prepared by dissolving $10 \mathrm{mg}$ of GABA in $10 \mathrm{~mL}$ of $0.1 \mathrm{~N} \mathrm{HCl}$. From stock solution, the working standards of concentration ranging from $1 \mathrm{ng}$ to $200 \mathrm{ng} / 5 \mu \mathrm{L}$ were prepared and final volume was made upto $10 \mathrm{~mL}$ with $0.1 \mathrm{~N} \mathrm{HCl}$.

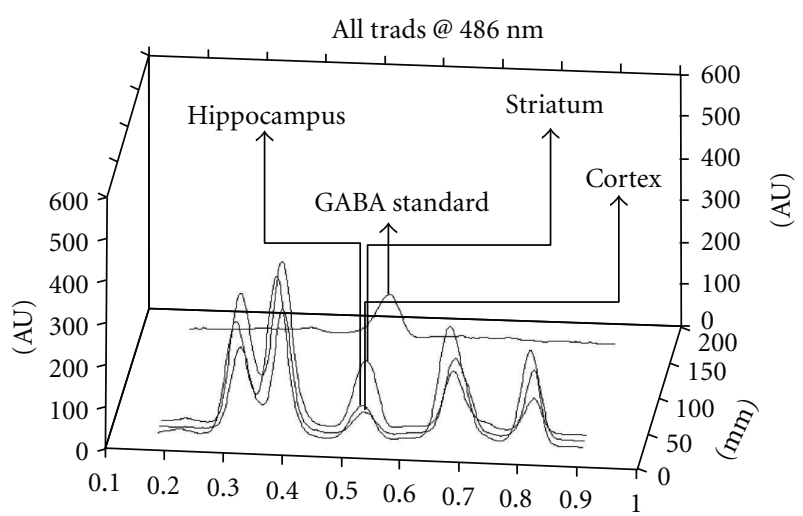

(Rf)

FIgURE 2: Peak match chromatogram of GABA standard and rat brain tissue.

TABLE 1: Method validation parameters for the quantification of GABA by HPTLC method.

\begin{tabular}{lc}
\hline Parameters & Results \\
\hline Instrumental precision (\% CV) & 0.5891 \\
Reproducibility (\% CV) & 0.4141 \\
Variability (\% CV) & \\
$\quad$ (i) Inter-day & 0.9453 \\
$\quad$ (ii) Intra-day & 1.3236 \\
Limit of detection (ng) & 1 \\
Limit of quantification (ng) & 10 \\
Specificity & Precise \\
Linearity (correlation coefficient) & 0.99940 \\
Range (ng spot & -1 ) \\
\hline
\end{tabular}

2.5. Preparation of Brain Tissue Samples. The overnight fasted rats $(n=6)$ were euthanized, brains were dissected out immediately and washed with ice cold normal saline to remove blood/blood clots and adhering tissues, if any. Brain regions such as cortex, striatum, and hippocampus were dissected over an ice-cold platform using the atlas of Paxinos and Watson [18]. Tissues were homogenized in $0.1 \mathrm{~N} \mathrm{HCl}$ (for every $10 \mathrm{mg}$ tissue $200 \mu \mathrm{L}^{-1}$ ) using a manual tissue homogenizer. The homogenates were transferred to polypropylene tubes and centrifuged at $4500 \mathrm{rpm}$ for $20 \mathrm{~min}$ at room temperature. The clear supernatant was then transferred into microcentrifuge tubes and used immediately for spot application.

2.6. Detection Reagent Preparation (0.2\% Ninhydrin Solution). $200 \mathrm{mg}$ of ninhydrin was weighed and dissolved in a small volume $(\sim 1 \mathrm{~mL})$ of acetone; to this, $1 \mathrm{~mL}$ of pyridine was added, and the volume was made up to $100 \mathrm{~mL}$ with acetone.

\subsection{Chromatographic Conditions}

(i) Stationary phase: Pre-coated HPTLC silica gel $\mathrm{GF}_{254}$ plates. 
(ii) Mobile phase: n-butanol: glacial acetic acid: water $(65: 18: 28 \mathrm{v} / \mathrm{v} / \mathrm{v})$.

(iii) Developing chamber: Twin trough glass chamber $(20 \times 10)$.

(iv) Developing mode: Ascending mode (multiple development).

(v) Chamber saturation time: $3 \mathrm{~h}$.

(vi) Instrument: HPTLC (Camag-version 1.3.4).

(vii) Applicator: Linomat V.

(viii) Scanner: Camag TLC scanner III.

(ix) Detection reagent: $0.2 \% \mathrm{w} / \mathrm{v}$ ninhydrin in acetone.

(x) Scanning wavelength: $486 \mathrm{~nm}$.

(xi) Environment condition: Room temperature/Relative humidity: 35\%-65\%.

2.8. Calibration Curve. $5 \mu \mathrm{L}$ of GABA standard solution ( $1 \mathrm{ng}$ to $200 \mathrm{ng}$ ) was applied as band in triplicates on pre-coated HPTLC plate. Spots were dried in hot air oven at $60-65^{\circ} \mathrm{C}$ for $\sim 1-2 \mathrm{~min}$, and the plate was developed using $\mathrm{n}$-butanol: glacial acetic acid: water $(65: 18: 28 \mathrm{v} / \mathrm{v} / \mathrm{v})$ as mobile phase. When the elution attained the vertical tip of plate, the plate was taken out and dried at $60-65^{\circ} \mathrm{C}$ for $3-4 \mathrm{~min}$ in hot air oven and subjected to second run in a similar fashion. Once the mobile phase reached the premarked solvent front, the plate was taken out and then dipped $(\sim 1 \mathrm{sec})$ in detection chamber containing $0.2 \% \mathrm{w} / \mathrm{v}$ ninhydrin reagent and dried again in hot air oven at $60-65^{\circ} \mathrm{C}$ for $\sim 2-3 \mathrm{~min}$. Eluted bands were scanned at $486 \mathrm{~nm}$ immediately, and the peak areas were recorded. The calibration curve was plotted using applied concentration versus areas.

2.9. Method Validation. The present method was validated in terms of Limit of Detection (LOD) and Limit of Quantification (LOQ), precision, recovery, reproducibility, and variability.

2.9.1. Limit of Detection (LOD) and Limit of Quantification (LOQ). Limit of Detection (LOD) and Limit of Quantification (LOQ) were determined from the calibration curve.

2.9.2. Precision. Instrumental precision for the present estimation was determined by repeated scanning of a single spot for seven times and the results were expressed as coefficient of variance $(\% \mathrm{CV})$.

2.9.3. Recovery. Accuracy of the method was determined by performing the recovery studies at two concentration levels. To $50 \mathrm{mg}$ of the brain tissue, $40 \mathrm{ng}$ (first level) and $80 \mathrm{ng}$ (second level) of GABA were added in separate tubes and the efficiency of the present extraction was evaluated in terms of percentage recovery.

2.9.4. Reproducibility. Reproducibility of the present method was validated by analyzing peak area of standard GABA solution ( $80 \mathrm{ng}$; in triplicates) for five times in a freshly prepared mobile phase. The results were expressed in $\% \mathrm{CV}$.

2.9.5. Variability. Variability of the present method was determined by analyzing the stored standard GABA solution $(80 \mathrm{ng})$ on the same day (interday assay) and on different days (intraday assay) and the results were expressed as \% CV.

2.10. Statistical Analysis. Results were expressed as \% coefficient of variance $(\mathrm{CV})$, which was calculated using the belowmentioned formula:

$$
\% \text { coefficient of variance }=(\mathrm{SD} / \mathrm{m}) \times 100
$$

$\mathrm{m}=$ mean value; $\mathrm{SD}=$ standard deviation for the mean.

\section{Results and Discussion}

GABAergic system plays a major role in pathophysiology of cerebral ischemia, epilepsy, sleep, and mood disorders. Estimation of GABA level in brain tissues will be a great tool in neuroscience research. Accurate estimation of GABA depends on several aspects, such as efficiency of extraction from tissue, specificity, and sensitivity of the method. In the present study, the estimation of GABA in the rat brain tissue was validated in terms of precision, recovery, reproducibility, and variability using HPTLC. Spectral overlay characteristics (Figure 1) and peak match chromatogram (Figure 2) bear out GABA content in tissues. Purity of GABA in the brain tissue sample was confirmed by comparing the UV absorption spectra at the start, middle, and end position of the bands.

Based on our earlier report [19], we fixed the mobile phase: n-butanol: glacial acetic and water $(65: 18: 28 \mathrm{v} / \mathrm{v} / \mathrm{v})$ with dual development procedure for achieving the best resolution of GABA $\left(\mathrm{R}_{\mathrm{F}}-0.49\right)$. GABA was visualized and detected by derivatizing the plate in $0.2 \% \mathrm{w} / \mathrm{v}$ ninhydrin after the second run. Excellent resolution and results were obtained when the test samples were applied immediately after preparation, saturating the developing chamber for at least $3 \mathrm{~h}$ with mobile phase, and drying the TLC plates, pre-/post-derivatization, at the recommended temperature $\left(60-65^{\circ} \mathrm{C}\right)$ and time period $(\sim 2-3 \mathrm{~min})$. The relationship between the standard concentration and peak area response was found to be linear in the range of 5-80 ng spot ${ }^{-1}$ with a correlation coefficient of 0.99940 (Table 1). LOD and LOQ for GABA were found to be 1 and $10 \mathrm{ng}$, respectively (Table 1 ). In the present study, the use of $0.1 \mathrm{~N} \mathrm{HCl}$ in $80 \%$ ethanol was found to be more efficacious in extracting GABA from brain tissues and dissolving the GABA standard. From the results, the average percentage recovery of GABA was found to be $97.98 \%$ at $40 \mathrm{ng}$ level and $96.15 \%$ at $80 \mathrm{ng}$ level (Table 2). GABA levels measured in the cortical, striatal, and hippocampal regions of the rat brain are shown in Table 3 . GABA content $\left(0.5-4 \mu\right.$ moles g $\left.^{-1}\right)$ determined using the present method was found to be consistent with earlier report $\left(0.1-0.5 \mathrm{mg} \mathrm{g}^{-1}\right.$ tissue) [20]. These data clearly shows that the present method is highly 


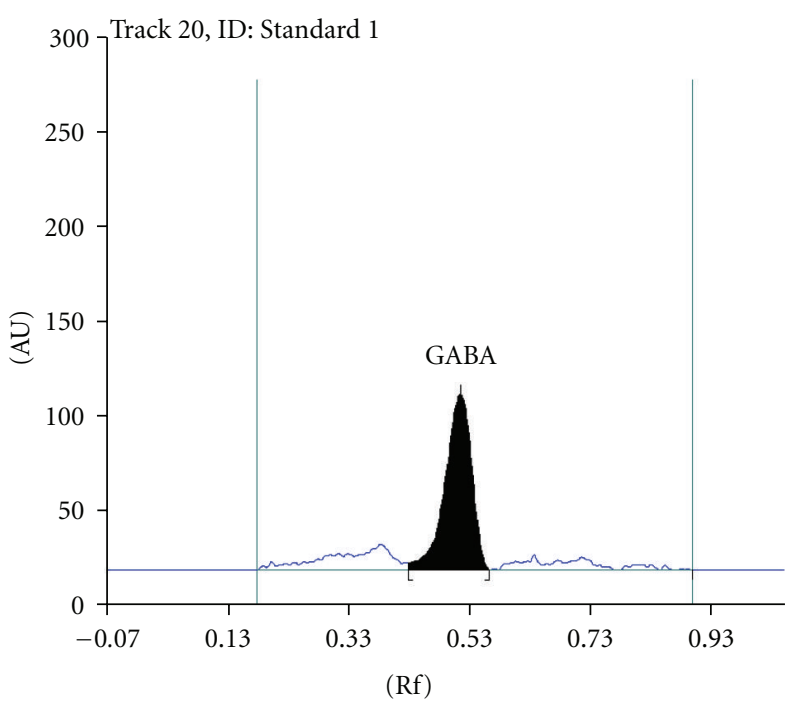

(a)

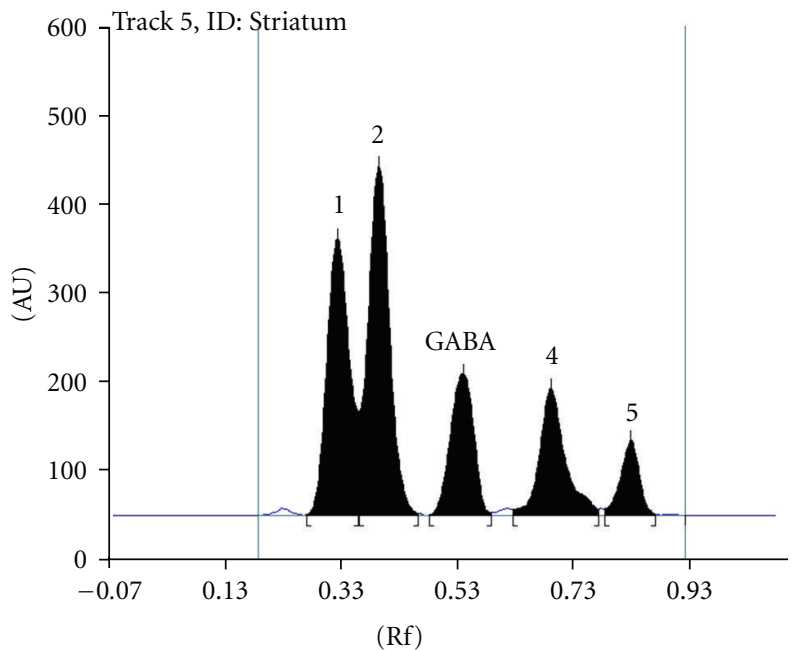

(c)

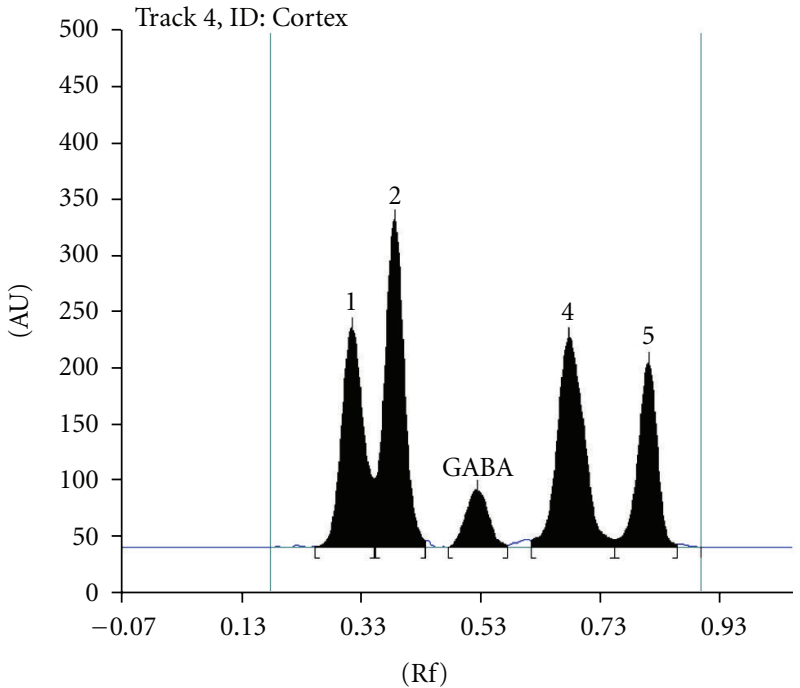

(b)

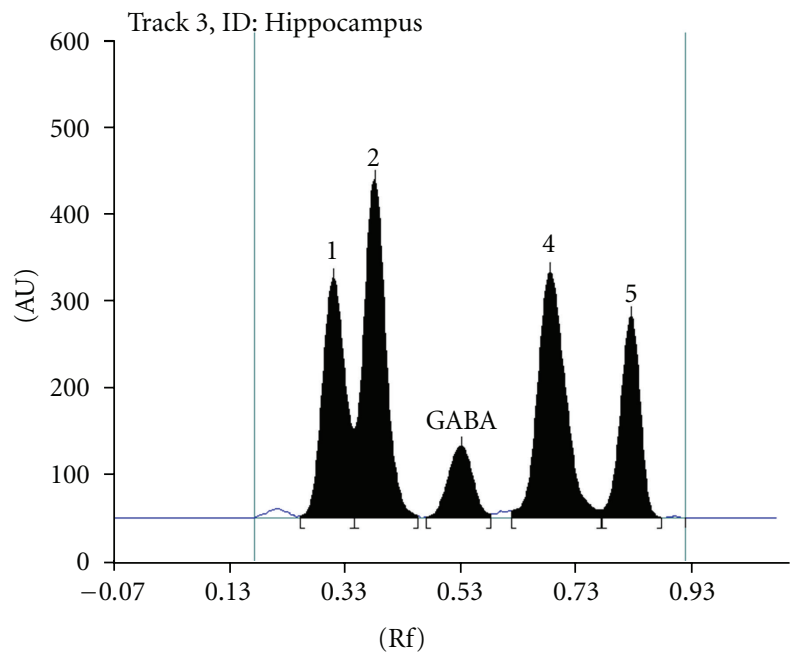

(d)

FIGURE 3: (a) HPTLC chromatogram of GABA in the different brain regions of rats-GABA standard. (b) HPTLC chromatogram of GABA in the different brain regions of rats-Cortex region. (c) HPTLC chromatogram of GABA in the different brain regions of rats-Striatal region. (d) HPTLC chromatogram of GABA in the different brain regions of rats-Hippocampal region.

TABLE 2: Recovery study of GABA by the proposed HPTLC method.

\begin{tabular}{lccccc}
\hline Test & Amount present $\mathrm{mg}^{-1}$ tissue $(\mathrm{ng})$ & Amount added $(\mathrm{ng})$ & Amount found $(\mathrm{ng})$ & Recovery $(\%)$ & Average recovery $(\%)$ \\
\hline \multirow{3}{*}{ GABA } & 235.98 & 40 & 272.58 & 98.77 & 97.98 \\
& 257.39 & & 289.04 & 97.19 & 96.78 \\
& 269.32 & \multirow{2}{*}{80} & 338.07 & 95.53 & 96.15 \\
\hline
\end{tabular}

efficient and sensitive in the extraction and estimation of GABA in brain tissues. Figures $3(a)-3(d)$ show the GABA peaks corresponding to the standard and different brain regions.

The advantages of the present method over existing techniques for the estimation of GABA are as follows: the present method is simple, robust, cost-effective, and less timeconsuming for large numbers of sample analysis.

\section{Conclusion}

The most obvious orthogonal advantages of HPTLC over other modern analytical techniques are speed of method development, visible chromatogram, cost factor and simultaneous analysis of multiple samples. The pharmacological implication of GABA is not only purported to central nervous system but also to the control of growth hormones. 
TABLE 3: GABA content found in different brain regions by the present HPTLC method.

\begin{tabular}{lc}
\hline Brain region & Content of GABA $\left(\mathrm{mg} \mathrm{g}^{-1}\right.$ wet tissue $)$ \\
\hline Cortex & $0.19 \pm 0.01$ \\
Striatum & $0.42 \pm 0.02$ \\
Hippocampus & $0.28 \pm 0.01$ \\
\hline
\end{tabular}

Values were expressed in mean $\pm \operatorname{SEM}(n=6)$.

Understanding the biological significance of GABA, a HPTLC method was developed to determine its level in rat brain tissues. To our knowledge, the present method is the first of its kind to estimate GABA level in rat brain tissue by HPTLC.

\section{Statement of Conflict}

The authors declare no conflicts of interest.

\section{Acknowledgment}

The authors acknowledge the Drugs and Pharmaceutical Division, Department of Science \& Technology, Govt. of India for providing the fellowship for CSB. Authors express thanks to Dr. K. Muthu Prathibha, Department of Physiology, Konaseema Institute of Medical Sciences, Andhra Pradesh, India for helping in preparing the paper and for English proofreading.

\section{References}

[1] J. Awapara, A. J. Landua, R. Fuerst, and B. Seale, "Free $\gamma$-aminobutyric acid in brain," The Journal of Biological Chemistry, vol. 187, no. 1, pp. 35-39, 1950.

[2] E. Roberts and S. Frankel, " $\gamma$-aminobutyric acid in brain: its formation from glutamic acid," The Journal of Biological Chemistry, vol. 187, no. 1, pp. 55-63, 1950.

[3] S. Udenfriend, "Identification of $\gamma$-aminobutyric acid in brain by the isotope derivative method," The Journal of Biological Chemistry, vol. 187, no. 1, pp. 65-69, 1950.

[4] S. R. Kleppner and A. J. Tobin, "GABA signaling: therapeutic targets for epilepsy, Parkinson's disease and Huntington's disease," in Opinion on Therapeutic Targets, vol. 5, pp. 219239, 2001.

[5] J. M. Pascual, F. Carceller, J. M. Roda, and S. Cerdán, "Glutamate, glutamine, and GABA as substrates for the neuronal and glial compartments after focal cerebral ischemia in rats," Stroke, vol. 29, no. 5, pp. 1048-1057, 1998.

[6] D. J. Nutt and A. L. Malizia, "New insights into the role of the GABA-benzodiazepine receptor in psychiatric disorder," British Journal of Psychiatry, vol. 179, pp. 390-396, 2001.

[7] R. B. Lydiard, "The role of GABA in anxiety disorders," Journal of Clinical Psychiatry, vol. 64, no. 3, pp. 21-27, 2003.

[8] C. B. Nemeroff, "The role of GABA in the pathophysiology and treatment of anxiety disorders," Psychopharmacology Bulletin, vol. 37, no. 4, pp. 133-146, 2003.

[9] I. Izquierdo and J. H. Medina, "Correlation between the pharmacology of long-term potentiation and the pharmacology of memory," Neurobiology of Learning and Memory, vol. 63, no. 1, pp. 19-32, 1995.
[10] I. Izquierdo and J. H. Medina, "GABA $A_{A}$ receptor modulation of memory: the role of endogenous benzodiazepines," Trends in Pharmacological Sciences, vol. 12, no. 7, pp. 260-265, 1991.

[11] J. H. Krystal, G. Sanacora, H. Blumberg et al., "Glutamate and GABA systems as targets for novel antidepressant and mood-stabilizing treatments," Molecular Psychiatry, vol. 7, supplement 1, pp. S71-S80, 2002.

[12] D. J. Nutt, J. C. Ballenger, D. Sheehan, and H. U. Wittchen, "Generalized anxiety disorder: comorbidity, comparative biology and treatment," International Journal of Neuropsychopharmacology, vol. 5, no. 4, pp. 315-325, 2002.

[13] S. Lindgren, N. E. Anden, and M. Grabowska-Anden, "A fluorimetric method for determination of GABA in tissues following cation exchange chromatography and condensation with o-phthalaldehyde," Journal of Neural Transmission, vol. 55, no. 3, pp. 243-252, 1982.

[14] M. Y. Khuhawar and A. D. Rajper, "Liquid chromatographic determination of $\gamma$-aminobutyric acid in cerebrospinal fluid using 2-hydroxynaphthaldehyde as derivatizing reagent," Journal of Chromatography B, vol. 788, no. 2, pp. 413-418, 2003.

[15] J. D. M. Pearson and D. F. Sharman, "A method for the estimation of $\gamma$ aminobutyric acid using gas liquid chromatography and electron capture detection," Journal of Neurochemistry, vol. 24, no. 6, pp. 1225-1228, 1975.

[16] A. Baldacci, R. Theurillat, J. Caslavska, H. Pardubská, R. Brenneisen, and W. Thormann, "Determination of $\gamma$ hydroxybutyric acid in human urine by capillary electrophoresis with indirect UV detection and confirmation with electrospray ionization ion-trap mass spectrometry," Journal of Chromatography A, vol. 990, no. 1-2, pp. 99-110, 2003.

[17] J. Kehr and U. Ungerstedt, "Fast HPLC estimation of $\gamma$-aminobutyric acid in microdialysis perfusates: effect of nipecotic and 3-mercaptopropionic acids," Journal of Neurochemistry, vol. 51, no. 4, pp. 1308-1310, 1988.

[18] G. Paxinos and C. Watson, The Rat Brain in Stereotaxic Coordinates, Academic Press, New York, NY, USA, 1986.

[19] C. S. Babu, A. G. Sunil, H. R. Vasanthi, V. S. Muthusamy, and M. Ramanathan, "Development and validation of an HPTLC method for simultaneous estimation of excitatory neurotransmitters in rat brain," Journal of Liquid Chromatography and Related Technologies, vol. 30, no. 19, pp. 2891-2902, 2007.

[20] B. S. Rao, T. R. Raju, and B. L. Meti, "Self-stimulation of lateral hypothalamus and ventral tegmentum increases the levels of noradrenaline, dopamine, glutamate, and AChE activity, but not 5-hydroxytryptamine and GABA levels in hippocampus and motor cortex," Neurochemical Research, vol. 23, no. 8, pp. 1053-1059, 1998. 


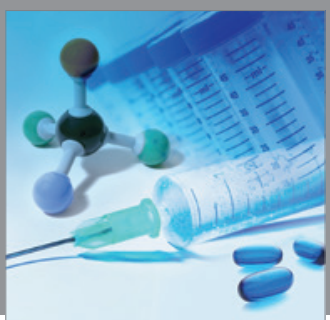

International Journal of

Medicinal Chemistry

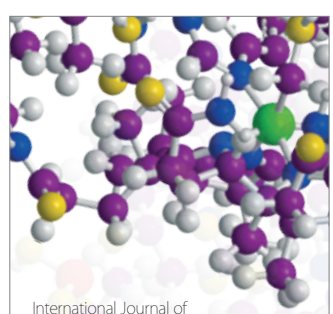

Carbohydrate Chemistry

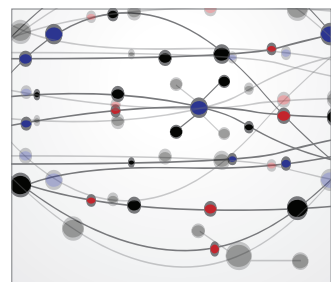

The Scientific World Journal
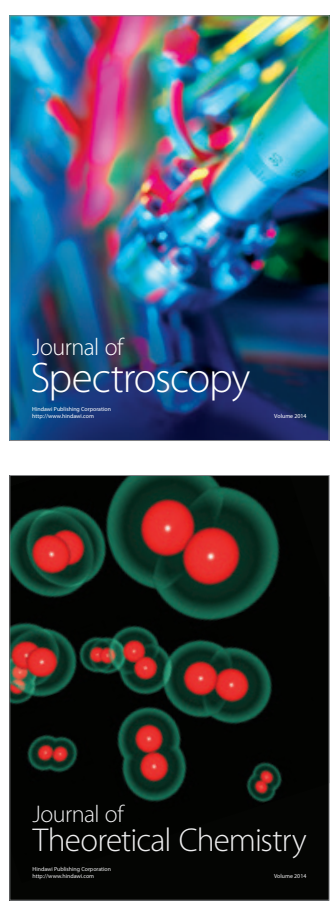
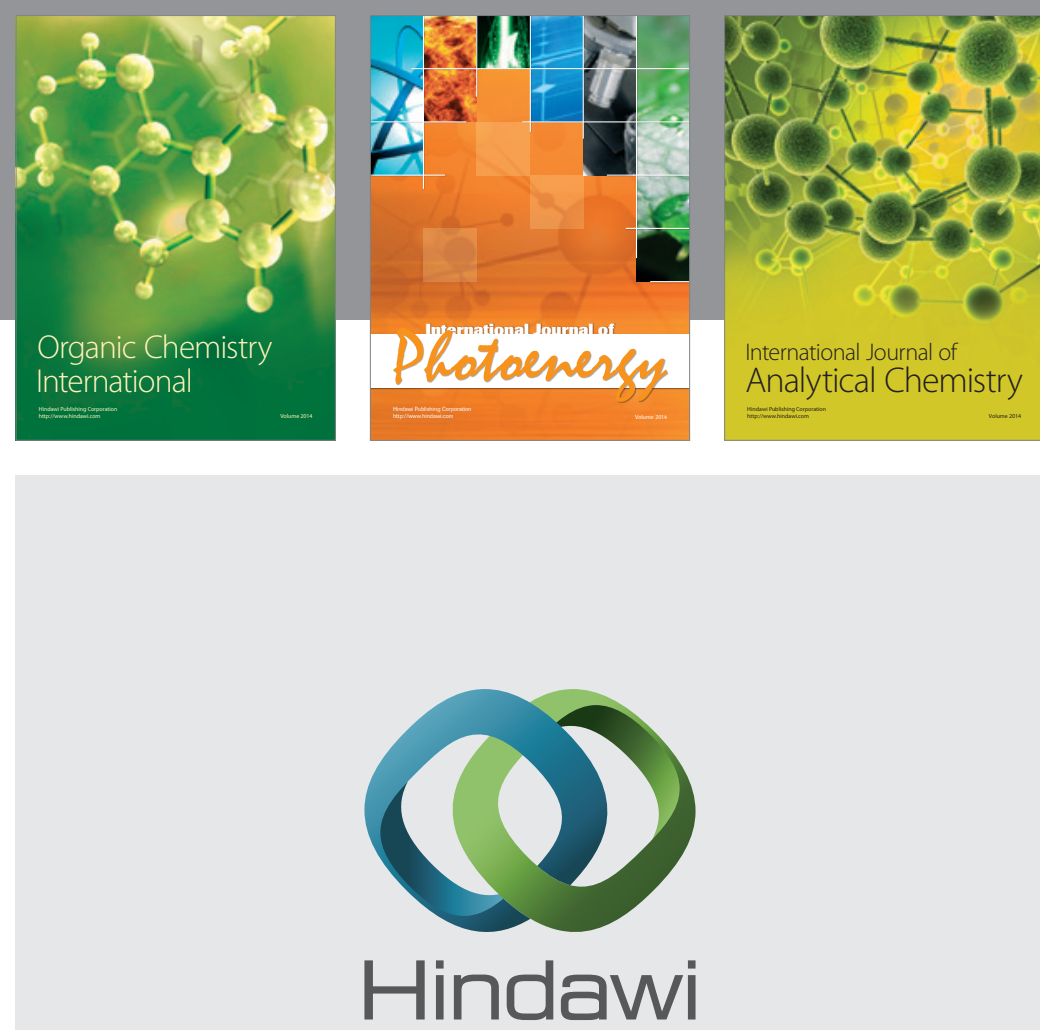

Submit your manuscripts at

http://www.hindawi.com
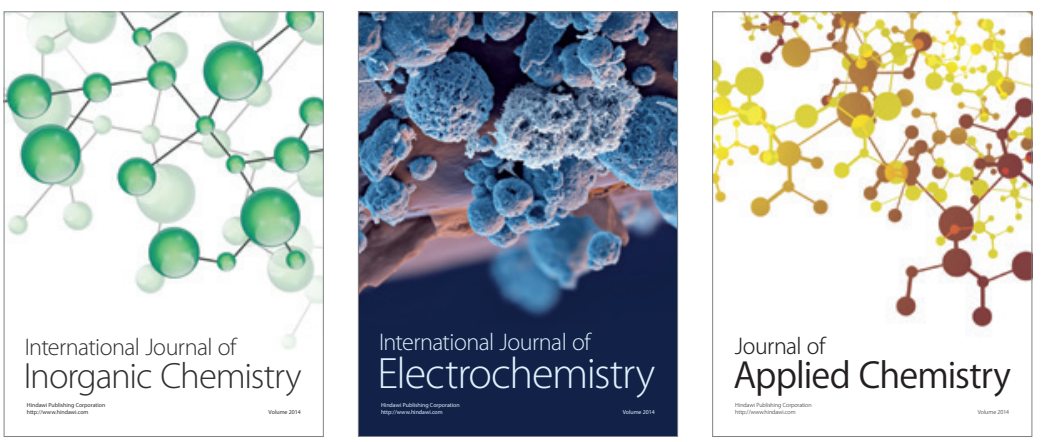

Journal of

Applied Chemistry
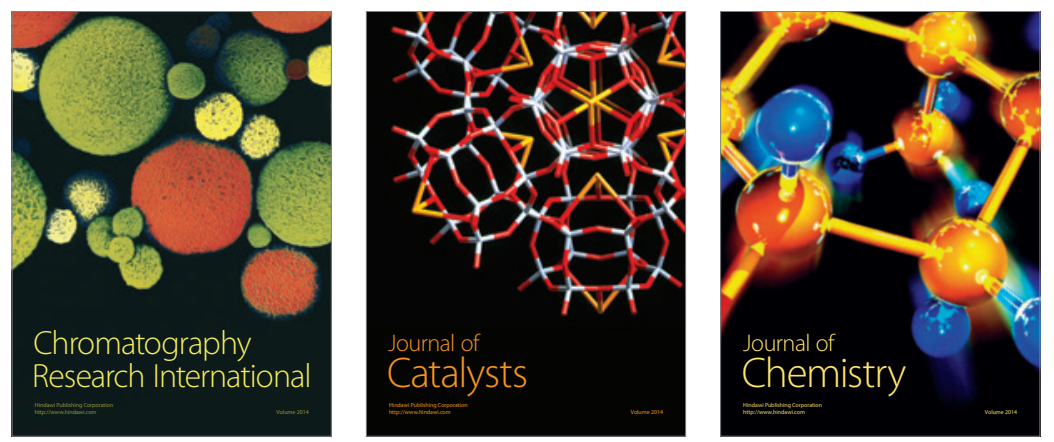
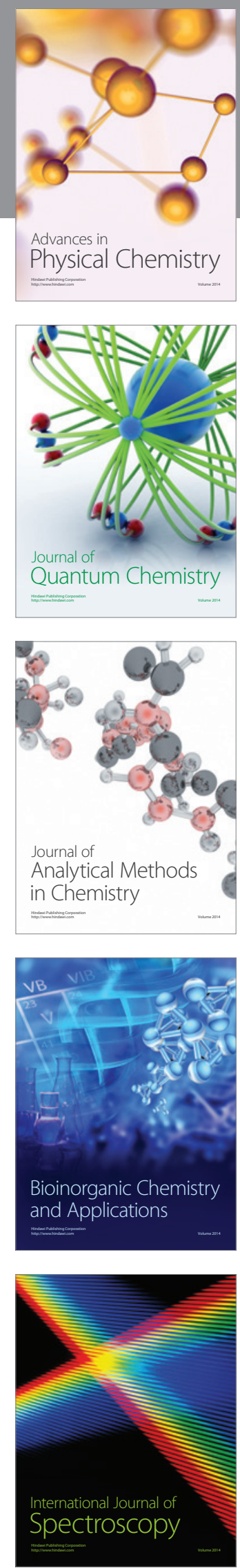